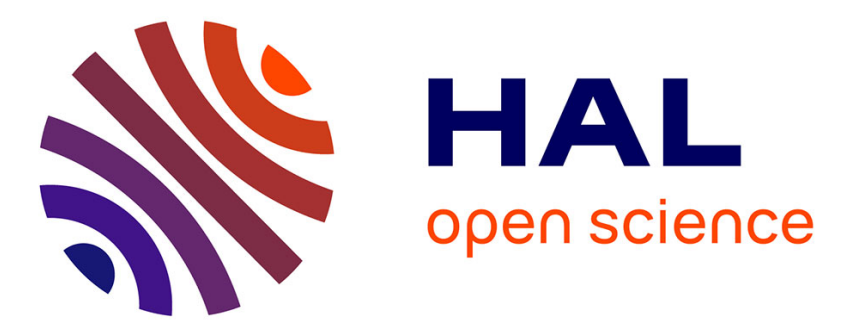

\title{
Degradation by-products of ancient paper leaves from wash waters
}

Maddalena Bronzato, Paolo Calvini, Carlo Federici, Anne-Laurence Dupont, Moreno Meneghetti, Valerio Di Marco, Barbara Biondi, Alfonso Zoleo

\section{- To cite this version:}

Maddalena Bronzato, Paolo Calvini, Carlo Federici, Anne-Laurence Dupont, Moreno Meneghetti, et al.. Degradation by-products of ancient paper leaves from wash waters. Analytical Methods, 2015, 7 pp.8197-8205. 10.1039/C5AY01114K . hal-01490972

\section{HAL Id: hal-01490972 \\ https://hal.science/hal-01490972}

Submitted on 22 Mar 2017

HAL is a multi-disciplinary open access archive for the deposit and dissemination of scientific research documents, whether they are published or not. The documents may come from teaching and research institutions in France or abroad, or from public or private research centers.
L'archive ouverte pluridisciplinaire $\mathbf{H A L}$, est destinée au dépôt et à la diffusion de documents scientifiques de niveau recherche, publiés ou non, émanant des établissements d'enseignement et de recherche français ou étrangers, des laboratoires publics ou privés. 


\section{Analytical Methods}

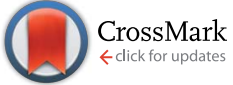

Cite this: Anal. Methods, 2015, 7, 8197

Received 30th April 2015

Accepted 2nd August 2015

DOI: 10.1039/c5ay01114k

www.rsc.org/methods

\section{Degradation by-products of ancient paper leaves from wash waters}

\author{
Maddalena Bronzato, ${ }^{a}$ Paolo Calvini, ${ }^{\mathrm{b}}$ Carlo Federici, ${ }^{\mathrm{c}}$ Anne-Laurence Dupont, ${ }^{\mathrm{d}}$ \\ Moreno Meneghetti, ${ }^{a}$ Valerio Di Marco, ${ }^{a}$ Barbara Biondi ${ }^{\mathrm{e}}$ and Alfonso Zoleo*a
}

\begin{abstract}
Water cleaning of paper leaves is a preliminary step in many customary deacidification treatments of ancient books in conservation workshops. Usually, the washing solutions are considered "waste waters" and they are thrown away. In this work, an analytical protocol for the analysis of wash waters for the assessment of the conservation state of ancient books is proposed. Wash waters of leaves under different conservation conditions of a 16th-century-printed book were investigated using UV-Vis, IR, Raman, NMR, EPR, XRF, ESI-MS, ICP-MS, CE-PDA and elemental microanalysis. Analysis of the wash water extracts allowed one to identify a large number of degradation by-products, ranging from low-molecular mass organic acids to cellulose oligomers. Reasons for the very different conservation conditions of the leaves emerged, indicating that wash water analysis provides a deep insight into the conservation state and composition of leaves as well as degradation reactions occurred on them.
\end{abstract}

\section{Introduction}

The relevance of paper as a material can be hardly overestimated, since it has been for centuries the support for delivering human knowledge. ${ }^{1}$ Although nowadays digital storage of information is ever growing, it is widely recognized that proper knowledge of the degradation reactions is essential for designing an efficient conservation treatment for paperbased documents.

As is well known, paper is a material prone to degradation: the synergistic action of the hydrolytic scissions and the oxidative reactions of cellulose chains in the amorphous domains can deeply affect the integrity of the writing support over time. ${ }^{2-4}$ For this reason, most aged papers show typical yellowing, brittleness and foxing stains, which are expected in the pages of old books. On the other hand, some aged papers are found to be stable, remaining relatively white and strong over time.

As a matter of fact, historical paper is a complex material, where cellulose and sizing substances (like gelatin, alum and

${ }^{a}$ Dipartimento di Scienze Chimiche, Università di Padova, via Marzolo 1, I-35131, Padova, Italy. E-mail: alfonso.zoleo@unipd.it; Fax: +39 0498275239; Tel: +39 0498275145

${ }^{b}$ Istituto per la Tutela delle Opere Grafiche (ITOG), via Pietro Sola 29, I-31059, Zero Branco, TV, Italy

'Dipartimento di Studi Umanistici, Universita' Ca' Foscari, Dorsoduro 3484/D, I-30123 Venezia, Italy

${ }^{d}$ Centre de recherche sur la conservation des collections (CRC, USR 3224), Muséum national d'Histoire naturelle, Ministère de la Culture et de la Communication, CNRS; CP 21, 36 rue Geoffroy-Saint-Hilaire, 75005 Paris, France

${ }^{e} I C B$, Padova Unit, CNR, Dipartimento di Scienze Chimiche, Università di Padova, 35131, Padova, Italy mineral fillers) interact in a complicated fashion: the variable quality of raw materials as well as the evolution in the techniques of paper production over the centuries explain the reasons for the observed different conservation conditions. Great attention has been paid to certain factors, such as gelatin content and trace metal content, which can play an important role in paper conservation. ${ }^{5}$ Gelatin was commonly used as a sizing material between 1400 and 1800 to prevent the bleeding of inks and to improve the resistance of a sheet of paper to the sorption of water. Gelatin has been derived from larger protein collagen, which is a major constituent of connective tissues in animals. Historically, gelatin was prepared by boiling animal tissues such as hide, skin and bones in water: ${ }^{6}$ in the treatment, peptide bonds are broken randomly giving rise to shorter amino acid chains. Despite their length, all the polypeptides and oligopeptides obtained by gelatin hydrolysis show a characteristic high amount of hydroxyproline bound in numerous amino acid triplets glycine-X-Y, where $\mathrm{X}$ and $\mathrm{Y}$ are most often proline and hydroxyproline, respectively.

The role of gelatin in paper durability has been investigated just in the last thirty years. It has been proposed that gelatin may act as an acid acceptor, meaning that the component amino acids act as a buffer. ${ }^{7-9}$ Studying the relationship between the actual condition of the historical papers and the amount of gelatin present, ${ }^{9-11}$ Barrett showed that increasing amounts of gelatin were related to historical samples under better conditions, in terms of improved endurance and reduced discoloration. In 2003, Dupont proposed that gelatin is likely to behave as a sacrificial component in paper due to the preferential hydrolysis of the protein molecules over those of the cellulose. ${ }^{14,15}$ On the contrary, it is known that iron and copper salts 
cause damage to paper, depolymerising cellulose chains and increasing the discoloration of paper. ${ }^{15-23}$ Metal ions such as $\mathrm{Al}(\mathrm{III}), \mathrm{Cu}(\mathrm{II}), \mathrm{Fe}(\mathrm{II})$, and $\mathrm{Fe}(\mathrm{III})$ are commonly found in paper and are powerful catalysts for hydrolysis and oxidation. Particularly in the Fenton reaction, the redox couple $\mathrm{Fe}(\mathrm{III}) / \mathrm{Fe}$ (II) gives rise to very reactive hydroxyl radicals, which are seen as one of the most important causes of oxidative degradation of cellulose. ${ }^{24,25}$ Because of these reasons, their occurrence in paper (as traces left by the production processes or as complexes in iron/ironcopper-based inks applied on the sheets) is regarded as a warning for possible active degradation reactions in paper. This affirmation is confirmed by EPR studies, performed on ancient paper, which have demonstrated that very badly deteriorated sheets of paper often show strong Fe(III) and in some cases also $\mathrm{Cu}(\mathrm{II})$ signals. ${ }^{26-29}$ The intricacy of paper degradation prompted numerous studies, most of them on modern cellulose samples, artificially degraded and analyzed usually with a limited range of techniques. Although these studies are very relevant, a comparison with naturally aged paper leaves is essential in designing improved artificial ageing methods and in evaluating their capacity of mimic natural ageing, especially over long ageing periods. On the other hand, very old paper documents are few and valuable, and usually a limited range of nondestructive techniques can be applied.

In this work, we show that the analysis of water used to wash ancient book leaves could be an efficient way to characterize the "health" condition of an ancient book: washing the leaves with water is a common deacidification method, often carried out routinely in paper conservation ateliers, and wash waters are considered "waste waters". Through the application of very broad multi-technique approaches (IR, NMR, Raman, EPR, XRF, CHNS microanalysis, ICP-MS, CE-PDA, and ESI-MS), we show that these water extracts are actually rich of paper degradation by-products.

Specifically, we characterized the water extracts obtained by washing the different leaves of a 16th century book, De Divina Providentia, during a deacidification treatment. ${ }^{30}$ According to simple visual inspection, the sheets showed different conservation conditions, ranging from very degraded to not degraded, and were distributed in a random way in the book. This is noteworthy because the sheets, being bound in the same volume, have been exposed to the same environmental conditions over the centuries. Therefore, this is a very rare case where a comparative study can be performed on naturally aged paper sharing the same environment over a long period of time, focusing in this way the attention on composition differences among the book leaves. The study shows that the analysis of water extracts is able to explain the different degradation of the sheets, therefore indicating that the collection of wash waters in deacidification treatments of ancient documents could be a powerful way to obtain information about the "health" condition of the book, as well as general information about the natural ageing of paper.

\section{Experimental}

\section{De Divina Providentia}

De Divina Providentia is a printed book, written by Domanino Lattanzio, a Mantuan Carmelite friar, and published by the editor Francesco Osanna in 1592. The book belongs to the Mantua Biblioteca Comunale Teresiana, but other copies of it are conserved in many Italian libraries. The ink used for the printed book is lamp black.

\section{Samples}

Aqueous extracts were obtained by washing very degraded (1), slightly degraded (2) and not degraded (3) leaves of De Divina Providentia. Leaf degradation was just qualitatively assessed by means of visual inspection, taking the paper yellowing and simultaneous brittleness as main parameters for the evaluation of the paper condition. Usually, higher levels of yellowing are related to lower DP in ancient paper. ${ }^{11-13}$

Each leaf was separately immersed in bidistilled water $(250$ $\mathrm{mL}$ ) at $50{ }^{\circ} \mathrm{C}$ and left to soak until the water temperature decreased to room temperature. This allowed extracting the water-soluble low molecular mass fraction formed in the leaves as a result of degradation reactions on cellulose and other paper components and induced by natural ageing. All the waters obtained from leaves under the same degradation conditions were collected in a single batch $(1 \mathrm{~L}$ for each type: very degraded, slightly degraded or not degraded), which was splitted for practical purposes in $50 \mathrm{~mL}$ aliquots. Each aliquot was labelled according to the level of degradation of the leaves (Table 1) and stored in the freezer $\left(-20^{\circ} \mathrm{C}\right)$ until use. For the analyses, small frozen amounts were melted and then quickly freeze-dried to obtain powders (numbered 1,2, and 3 for the respective extracts). It has been estimated that around $25 \mathrm{mg}$ of powder can be obtained from $1 \mathrm{~g}$ of paper for all the three sample solutions.

\section{Methods}

The $\mathrm{pH}$ of three extracts (Table 1) was measured by using a standard pH meter (Inolab, Sigma Precision S.r.l.).

The FT-IR spectra were collected on a Bruker Equinox 55 spectrometer, equipped with an ATR Sampling Accessory (diamond cell) and a MCT detector. A small amount of powder of each sample was deposited uniformly on the ATR plate. Each IR spectrum was the result of 64 scans with a $4 \mathrm{~cm}^{-1}$ resolution. In the figures, each IR spectrum has been normalized with respect to the maximum absorbance. The reference sample of Whatman paper was a piece $(0.5 \times 0.5 \mathrm{~cm})$ of Whatman filter paper n. 44 (ashless, $<0.01 \%$ ash). The UV-Vis spectra were acquired on a Cary 5 double beam UV-Vis-NIR spectrophotometer. The measurements were carried out on dilute solutions of all samples $\left(20 \mu \mathrm{g}\right.$ of powder in $2 \mathrm{~mL}$ of bidistilled $\mathrm{H}_{2} \mathrm{O}$ ). Standard cuvettes with $1 \mathrm{~cm}$ path length were used. The ${ }^{1} \mathrm{H}$ NMR spectra

Table 1 General properties of the water extracts

\begin{tabular}{llll}
\hline & Origin & $\mathrm{pH}$ & Colour \\
\hline Ext 1 & Very degraded leaves & 4.64 & Very brown \\
Ext 2 & Slightly degraded leaves & 5.92 & Light brown \\
Ext 3 & Not degraded leaves & 7.67 & Yellowish
\end{tabular}


and the ${ }^{1} \mathrm{H}$-detected heteronuclear multiple quantum coherence (HMQC) spectra were obtained on a Bruker Avance DMX600 spectrometer, equipped with a three-axis gradient TXI probehead. The spectra were obtained at room temperature on solutions of the three samples in $\mathrm{D}_{2} \mathrm{O}$. A Renishaw in via Raman microscope (633 nm exciting line) was used to perform measurements on the powders of all the samples. The Raman measurements of Extract 1 were carried out with a $5 \times$ objective, $100 \%$ laser power (15 mW), 5 accumulations and 15 s scan time. The spectra of all samples show a strong fluorescence band from polyelectronic compounds formed during degradation. ${ }^{31}$ Fluorescence was quenched using the SERS technique to obtain the Raman spectrum. SERS signals were recorded in the presence of naked gold nanoparticles of about $20 \mathrm{~nm}$ obtained by laser ablation synthesis in solution (LASiS). ${ }^{32,33}$ To the purpose of the present analysis, $40 \mathrm{~mL}$ of the gold nanoparticle solution ( $3 \mathrm{nM}$ ) were mixed with $10 \mathrm{~mL}$ of sample water solution and the obtained mixture was left to evaporate on a slide. The spectra were acquired directly on various parts of the stain using a $50 \times$ objective, $5 \%$ laser power $(0.75 \mathrm{~mW}), 5$ accumulations and $30 \mathrm{~s}$ scan time. The samples did not show variations before and after the laser application.

The continuous-wave EPR spectra have been acquired on a Bruker ER200 instrument, equipped with a TE102 probehead. The microwave frequency was about $9.5 \mathrm{GHz}$, modulation amplitude was $0.2 \mathrm{mT}$ and the microwave power was $2 \mathrm{~mW}$.

XRF measurements were carried out on a XRF system constituted by an X-ray tube with an Mb anode (operated at 20 $\mathrm{kV}$ and $1.2 \mathrm{~mA}$ in helium stream). The measurement time was set at $300 \mathrm{~s}$.

Thermo Scientific Flash 2000 was used for CHNS microanalysis: it was constituted by a primary combustion column at $950{ }^{\circ} \mathrm{C}$, where few $\mathrm{mg}$ of samples were introduced into a separation column for the combustion gases, and a TCD detector.

Calculations and analytical procedures were carried out using a specific software tool (Flash 2000 Eager Xperience), which allows for the use of $K$-factor as a method of calibration and of BBOT 2,5-bis-(5-tert-butyl-benzoxazol-2-yl)-thiophen as the standard.

ICP analyses were performed on an ICP-MS Agilent 7700, equipped with a fragmentation chamber in a helium stream and a signal correction system based on the use of internal standards.

Mass spectra (electrospray ionization source, ESI-ToF) of Extract 3 were recorded by operating in positive-ion mode by means of PerSeptiveBiosystem Mariner instrument (Framingham, MA). The sample was prepared by dissolving $0.2 \mathrm{mg}$ of Extract 3 powder in $250 \mu \mathrm{L}$ of a solution $1: 1$ acetonitrile-water. The mobile phase used was a $1: 1$ acetonitrile-water solution added with $0.1 \%$ formic acid.

The mass spectra were run in two different mass ranges, from 100 to $4000 \mathrm{Da}$ and from 100 to $1000 \mathrm{Da}$. As most of the peaks fell in the lowest mass range, only the lower mass range was deeply studied.

The investigation and quantification of the low molecular mass organic acids (LMMOA) were performed by means of CEPDA (capillary electrophoresis with photodiode array detection), using a method previously developed and applied on aqueous extracts obtained from artificially aged papers and 18th and 19th century books of various pulp compositions. ${ }^{34,35}$ Electrophoretic separations were performed by means of a P/ACE MDQ capillary electrophoresis instrument (Beckman Coulter). The system operation and data acquisition were performed using 32 Karat 5.0 software (Beckman Coulter). A bare fused silica capillary of $75 \mu \mathrm{m}$ internal diameter and $65 \mathrm{~cm}$ length was used (55 $\mathrm{cm}$ effective length to the detector window). Prior to the sample injection, the capillary was rinsed by flushing $2 \mathrm{~min}$ with $\mathrm{NaOH} 0.1 \mathrm{M}$ and 2 min with deionised water. The third step involves the conditioning of the capillary for $3 \mathrm{~min}$ with the electrolyte (buffer). The buffer was prepared with PDC $5 \mathrm{mM}$ as the background electrolyte (BGE) and CTAB $0.5 \mathrm{mM}$, at pH 5.6, adjusted with $\mathrm{NaOH} 1$ and $0.1 \mathrm{M}$. The injection was performed in the hydrodynamic mode by applying a pressure of 0.7 psi for $4.5 \mathrm{~s}$. A separation voltage of $-25 \mathrm{kV}$ was applied to the anodic end. The resulting current was 20.1-20.5 $\mu \mathrm{A}$. Indirect UV detection at $350 \mathrm{~nm}$ was used with reference at $200 \mathrm{~nm}$ and a band width of $20 \mathrm{~nm}$ with a photodiode array. More details on the methods can be found elsewhere. ${ }^{33}$

Before analysis, all the solutions used in the measurements (distilled water, 0.1 M NaOH solution, conditioning and separation buffer solutions and sample solutions) were filtered using a PTFE syringe filter $(0.45 \mu \mathrm{m}$; Millipore).

The CE-PDA method was applied to the aqueous extracts of three leaf types; among other yet unknown peaks, all electropherograms showed the full range of organic acids used as models (Table 2).

Peak attributions in the electropherograms were based at first on the migration time $\left(t_{\mathrm{m}}\right)$. In order to double-check for the presence of different acids, the model organic acids were added one at a time to the sample solutions (spiking) and the samples were re-analyzed. Even in the case of slight variations in $t_{\mathrm{m}}$, the differences in the intensity of a specific peak after the addition of the corresponding standard acid helped in the identification.

It was not possible to assign the peaks just by the simple comparison of the electropherograms of the samples and the standard acids, as the matrix effect affected the migration time of the different LMMOA in the samples.

The quantification of the individual acids in the three samples was carried out by extrapolation from the respective calibration curves, which were built using six solutions $(5,10$, 20, 50, 75 and $100 \mathrm{ppm}$ ) of each model LMMOA (Table 2) with six levels of concentration produced using one individual stock solution. Each calibration point corresponds to three injections.

Table 2 Concentration (ppm) of acetic (A), formic (F), succinic (S), glycolic (G) and lactic (L) acid measured by CE-PDA

\begin{tabular}{llllll}
\hline & $\mathrm{A}(\mathrm{ppm})$ & $\mathrm{F}(\mathrm{ppm})$ & $\mathrm{S}(\mathrm{ppm})$ & $\mathrm{G}(\mathrm{ppm})$ & $\mathrm{L}(\mathrm{ppm})$ \\
\hline Ext 1 & 4.5508 & 2.5864 & 7.4143 & 0.8176 & 3.1986 \\
Ext 2 & 4.1926 & 2.2248 & 5.2780 & 0.6413 & 2.9259 \\
Ext 3 & 6.3475 & 4.0322 & 8.1977 & 1.6300 & 4.6359
\end{tabular}




\section{Results and discussion}

The three water sample solutions respectively obtained by very degraded, slightly degraded and not degraded leaves of $D e$ Divina Providentia showed an intense color, indicating the high capacity of water to extract degradation by-products from the paper leaves. Every single solution has been analyzed by means of a wide range of spectroscopic techniques.

\section{Extract 1}

The UV-visible spectrum of Extract 1 (Fig. 1, trace a) is characterized by an intense absorption in the ultraviolet range and a slow decrease in the visible range up to $700 \mathrm{~nm}$ : the broad absorption between 200 and $300 \mathrm{~nm}$ is normally attributed to n$\pi^{*}$ and $\pi-\pi^{*}$ transitions, which are typical of unsaturated and possibly conjugated groups. ${ }^{28,34-37}$

A shoulder at $280 \mathrm{~nm}$, related to carbonylic and carboxylic n$\pi^{*}$ transitions, can be also observed. The appearance of the long tail in the visible range suggests the presence of conjugated systems in the degradation products dissolved in the extracts..$^{\mathbf{3 0 4}}$

The smooth profile of the FTIR spectrum (Fig. 2, upper panel, trace a), as compared with the rugged profile of monomers, suggests the presence of cellulose oligomers composed of about eight to thirteen units, which represents the upper limit of their water solubility. This assumption has been confirmed by the preliminary HPLC-MS analysis. ${ }^{30}$

The FTIR spectrum is mainly characterized by an intense band at $1630 \mathrm{~cm}^{-1}$ : in the literature,,$^{30,38,39}$ this signal has been typically found in IR spectra of fully degraded papers and it has been identified as an envelope of vibrational modes assigned to various functional groups due to oxidation and dehydration reactions, like carbonyl and carboxyl groups (1700-1730 $\left.\mathrm{cm}^{-1}\right),{ }^{41,42}$ carboxylates $\left(1550-1610 \mathrm{~cm}^{-1}\right),{ }^{36,41} \alpha-$ diketones (frequently present in their enol form) and/or $\alpha, \beta$ unsaturated carbonyl and carboxyl groups (about 1660 $\mathrm{cm}^{-1}$ ), ${ }^{36-38,43} \mathrm{C}=\mathrm{C}$ double bond (about $\left.1640 \mathrm{~cm}^{-1}\right)^{36,43,44}$ and adsorbed water (about $1635 \mathrm{~cm}^{-1}$ ) bound to carbohydrates through hydrogen bonds. The Raman spectrum of Extract 1 shows a peak at $1575 \mathrm{~cm}^{-1}$, recognized in the literature as a "marker" for oxidative processes occurred on paper (Fig. 2,

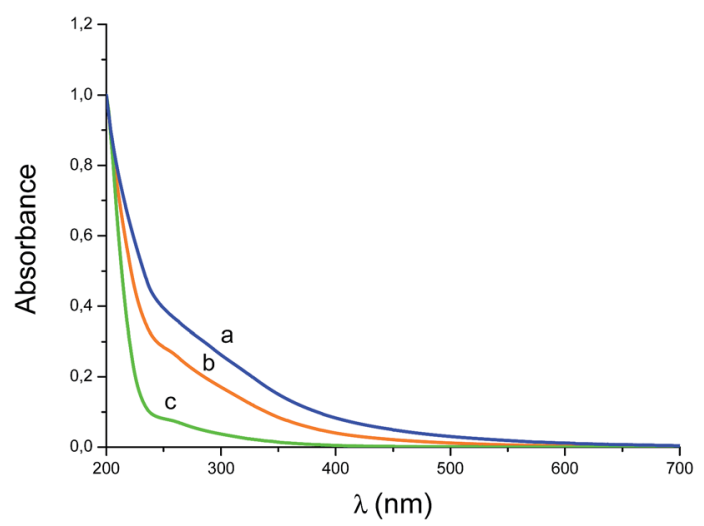

Fig. 1 UV-Vis spectra of Extract 1 (a), Extract 2 (b) and Extract 3 (c).

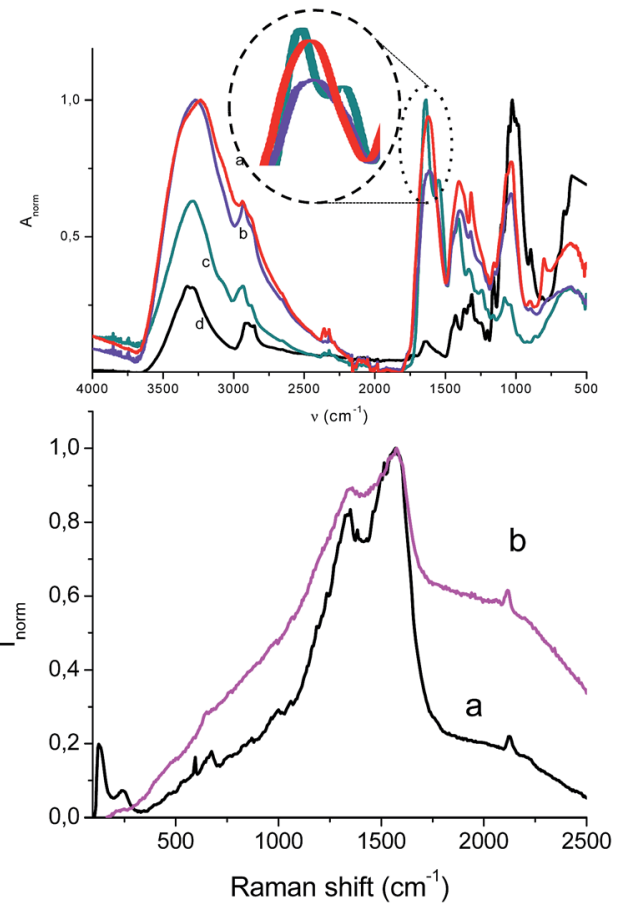

Fig. 2 Upper panel: IR spectra of Extract 1 (a, red), Extract 2 (b, purple), Extract 3 (c, green), and Whatman paper (d). The region around 1600 $\mathrm{cm}^{-1}$ is magnified to show the doublet of the green trace $c$. Lower panel: Raman spectra of Extract 1 (a) and Extract 2 (b).

lower panel, trace a). This signal is normally assigned to $\mathrm{C}=\mathrm{C}$ symmetric stretching and $\mathrm{O}=\mathrm{C}-\mathrm{O}$ asymmetric stretching. ${ }^{30,31}$ The presence of the carboxylate groups, identified in the FTIR and Raman spectra, is in agreement with the relatively high pH value of Extract 1 (Table 1): it indicates that the carboxylic groups are mainly present in their deprotonated form, accounting for the high solubility of Extract 1 only in a polar solvent like water. ${ }^{45}$ Carboxylate species arise from low molecular mass organic acids, whose study in ancient and historical papers has been widespread in the literature, and/or from oxidized glycosidic units of cellulose chain or, as in this case, oligomers (see below).

The HMQC spectrum (Fig. 3, trace a) shows signals at 3.5-77 ppm and 4.1-71 ppm, which can be attributed respectively to the $\mathrm{H}_{3}-\mathrm{C}_{3}$ and $\mathrm{H}_{5}-\mathrm{C}_{5}$ spin systems of glucuronic acid or its salt glucuronate, ${ }^{\mathbf{4 6 - 4 8}}$ verifying the formation of oxidized glucose derivatives in the cellulose oligomers. This latter signal (4.1-71 ppm) can be due also to the $\mathrm{H}_{2}-\mathrm{C}_{2}$ spin system of gluconate. ${ }^{49}$

The cellulose oligomer degradation seems to proceed to the further step of decarboxylation, as pointed out by the peak at 3.42-62 ppm attributed to xylosic units $\left(\mathrm{H}_{5}-\mathrm{C}_{5}\right)$. The decarboxylation processes, giving rise to xylosic units, are commonly observed in carbohydrate samples upon ozone treatment and for this reason they represent a reliable proof of oxidative paths occurring on cellulose..$^{50,51}$ In this case, it is unlikely that the xylosic rings can be attributed to residual hemicellulose, as the paper sheets, from which the sample was extracted, are composed by pure linen, a pure cellulose material usually without hemicellulose. 

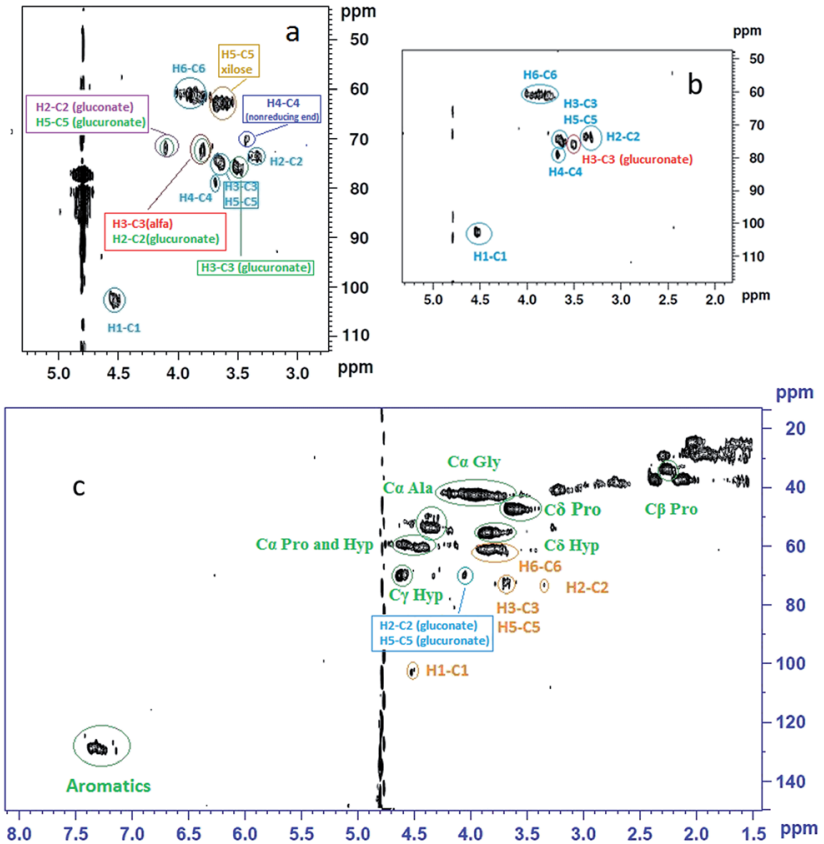

Fig. 3 HMQC spectra of Extract 1 (a), Extract 2 (b) and Extract 3 (c).

Finally, the correlation peak at $3.8-73 \mathrm{ppm}$ is assigned to $\alpha$ glucose $\left(\mathrm{H}_{3}-\mathrm{C}_{3}\right.$ (alfa)): this species occurs only if single molecules of glucose are present in the degradation by-products. Its detection provided a further proof of the occurred acidic hydrolysis on the cellulose chains of the book leaves. This datum has been also confirmed by the preliminary HPLC-MS. ${ }^{30}$

Low molecular mass organic acids (LMMOA), such as glycolic, formic, succinic, lactic and acetic acid, were investigated. Their identification and quantification were performed by means of a developed and largely tested protocol based on capillary electrophoretic analysis, CE-PDA: their concentration in each extract is reported in Table 2.

A deep study of the metal content of the sample has been performed as well: much effort has been dedicated to the detection and quantification of metal ions, with particular attention on $\mathrm{Fe}(\mathrm{II}) / \mathrm{Fe}(\mathrm{III})$ and $\mathrm{Cu}(\mathrm{II})$ species.

The species can originate from the metal-based ink applied on paper and/or from the water and the metallic tools used in paper manufacturing.

Considering De Divina Providentia, the painting medium used in the text is lamp black ink composed by fine soot collected from incompletely burned carbonaceous materials. This indication implies that the possibly detected metal ions in our samples were directly present in the paper matrix. EPR, ICPMS and XRF analysis were carried out on Extract 1 in order to probe the type, coordination and the amount of metal ions.

The EPR spectrum of Extract 1 (Fig. 4, trace a) is characterized by a sharp line around $150 \mathrm{mT}$ and by a weaker broad line, between 300 and $350 \mathrm{mT}$, resolved in six hyperfine lines.

The sharp line is due to Fe(III) complexes far from the cubic symmetry ("rhombic site"), attributed generally to strongly bound $\mathrm{Fe}(\mathrm{III})$. A second broad line around $350 \mathrm{mT}$ is generally observed in ancient papers, due to $\mathrm{Fe}(\mathrm{III})$ in quasi-cubic

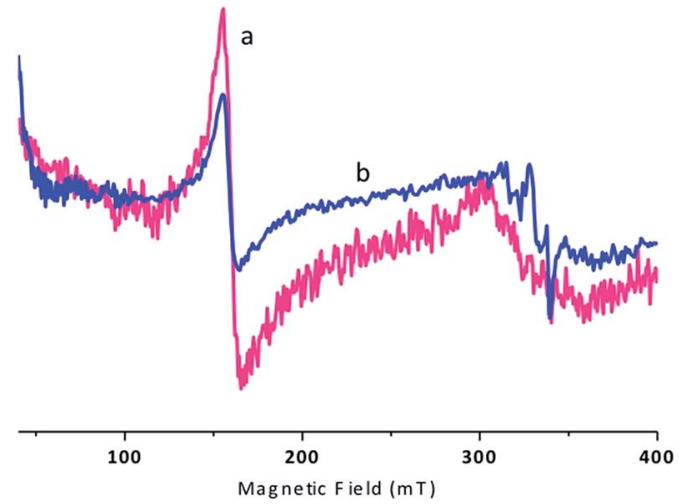

Fig. 4 EPR spectra of Extract 1 (a) and Extract 2 (b).

symmetry and is ascribed to hydrated Fe(III) or Fe(III) weakly bound to cellulose. This line is lacking in our samples. The six lines between 300 and $350 \mathrm{mT}$ are due to $\mathrm{Mn}$ (II). ${ }^{26-29}$ No $\mathrm{Cu}$ (II) signals can be observed.

The significant presence of Fe was also confirmed by XRF (Table 3) and ICP-MS (Table 4), which, unlike EPR, allowed also the detection of $\mathrm{Al}$ species. The presence of $\mathrm{Al}(\mathrm{III})$ ions in the wash waters could indicate the use of alum during the sizing procedure of the sheets, from which Extract 1 was obtained. Alum is recognized as a paper degradation agent, due to its catalytic action on hydrolysis, and its presence could explain the higher degradation level of these leaves.

However, the absence of detectable sulphur signal through XRF and the very low amount of sulphur according to elemental analysis (Table 5) suggest that $\mathrm{Al}$ might derive from alternative sources, e.g. from rags maceration. If $\mathrm{Al}$ had been derived from rock alum $\mathrm{KAl}\left(\mathrm{SO}_{4}\right) \cdot 12 \mathrm{H}_{2} \mathrm{O}$ (which was the alum used before the 19th century) a comparable amount of $\mathrm{Al}$ and $\mathrm{S}$ would have been obtained, which is not the case. On the other hand, Al could be released easily from the silicate stones of the tub used during alkaline leaching (with lye) of rags, a step often used in rags maceration.

\section{Extract 2}

Extract 2 shows a similar composition to Extract 1 . However, the lower intensity of the IR signal around $1600 \mathrm{~cm}^{-1}$ (Fig. 2, upper

Table 3 Results of XRF analysis (elements found)

\begin{tabular}{lllllllllll}
\hline Ext 1 & \multirow{2}{*}{$\mathrm{Al}$} & \multirow{2}{*}{$\mathrm{Si}$} & $\mathrm{P}$ & $\mathrm{Cl}$ & $\mathrm{K}$ & $\mathrm{Ca}$ & $\mathrm{Cr}$ & $\mathrm{Mn}$ & $\mathrm{Fe}$ & $\mathrm{Cu}$ \\
Ext 2 & & & $\mathrm{P}$ & $\mathrm{Cl}$ & $\mathrm{K}$ & $\mathrm{Ca}$ & & & $\mathrm{Fe}$ & $\mathrm{Cu}$ \\
Ext 3 & & & $\mathrm{P}$ & $\mathrm{Cl}$ & $\mathrm{K}$ & $\mathrm{Ca}$ & & & $\mathrm{Fe}$ &
\end{tabular}

Table 4 Results of ICP-MS analysis

\begin{tabular}{llll}
\hline & Al (ppm) & Fe (ppm) & Zn (ppm) \\
\hline Ext 1 & $66.6(1.7)$ & $8.8(2.5)$ & $74(24)$ \\
Ext 2 & $24.0(1.7)$ & $5.3(2.5)$ & $8(24)$ \\
Ext 3 & $37.1(1.7)$ & $2.9(2.5)$ & $47(24)$
\end{tabular}


Table 5 Results of elemental analysis

\begin{tabular}{llll}
\hline & Extract 1 & Extract 2 & Extract 3 \\
\hline $\mathrm{C}$ & $38.14 \%$ & $37.67 \%$ & $38.97 \%$ \\
$\mathrm{H}$ & $5.08 \%$ & $5.19 \%$ & $5.76 \%$ \\
$\mathrm{~N}$ & $4.53 \%$ & $3.93 \%$ & $10.19 \%$ \\
$\mathrm{~S}$ & $0.16 \%$ & $0.26 \%$ & $0.34 \%$ \\
\hline
\end{tabular}

panel, trace b), the lack of NMR peaks attributed to $\alpha$-glucose and to xylose (Fig. 3, panel b), the lower intensity of the band at 280 $\mathrm{nm}$ in the UV-Vis spectra with a shorter tail in the visible range of the absorption (Fig. 1, trace b) and the slightly lower amount of LMMOA (Table 1) indicate that Extract 2 underwent milder hydrolysis and oxidation reactions than Extract 1. This assumption has been also confirmed by the elemental analysis results (Table 5). According to these, the formulae of compounds in Extracts 1 and 2 are respectively $\mathrm{C}_{3.18} \mathrm{H}_{5.09} \mathrm{~N}_{0.32} \mathrm{O}_{3.26}$ and $\mathrm{C}_{3.13} \mathrm{H}_{5.19} \mathrm{~N}_{0.28} \mathrm{O}_{3.31}$. In a previous work, ${ }^{30}$ analyses demonstrated that Extract 1 was mainly constituted by cellulose oligomers.

Similar spectroscopic features of Extract 2 suggest that an analogue situation holds. Therefore, we can consider sugars and glucose-derivates as main components of the two samples, neglecting the $\mathrm{N}$ content, and we can round the two empirical formulae to the closest integers, as $\mathrm{C}_{64} \mathrm{H}_{102} \mathrm{O}_{65}$ for Extract 1 and $\mathrm{C}_{63} \mathrm{H}_{104} \mathrm{O}_{66}$ for Extract 2. These latter formulae correspond approximately to a ten-ring chain in a cellulose polymer. The calculated degree of unsaturation for this tenring chain is 14 for Extract 1, while it is 12 for Extract 2. Taking into account that a ten-ring cellulose-type chain corresponds to 10 unsaturations, and assuming that the other possible unsaturations are only due to double bonds $(\mathrm{C}=\mathrm{C}$ and $\mathrm{C}=\mathrm{O})$, we estimate every ten rings an average of 4 double bonds for Extract 1 and 2 double bonds for Extract 2 .
The compounds in Extract 1 show one unsaturation every 2.5 pyranose rings, while in Extract 2 they bear one unsaturation every 5 rings. This result is in agreement with the spectroscopical data, indicating that Extract 2 arises from paper with a minor extent of degradation compared to Extract 1.

\section{Extract 3}

The UV-Vis spectrum of Extract 3 (Fig. 1, trace c) does not show a long tail in the visible range, and its carbonyl and carboxyl band is less intense. The FTIR spectrum of Extract 3 (Fig. 2, upper panel, trace c) presents an intense doublet at $1630 \mathrm{~cm}^{-1}$ and $1540 \mathrm{~cm}^{-1}$ (see the magnified inset in Fig. 2, upper panel), which is typical of "amide I" and "amide II" vibrational modes, and it is indicative of the presence of peptides, most likely coming from the gelatin used for sizing.

These results are supported by the HMQC data (Fig. 3, panel c): the NMR spectrum is characterized by a large amount of peaks, mostly assigned in the literature to the amino acids typically present in the collagen structure, i.e. glycine $(33 \%$ in animal gelatin), alanine (10\%), proline (12\%) and hydroxyproline $(10 \%)$ residues. $^{52,53}$ Some cellulose signals are present, as well, while the correlation peak at 7.3-129 ppm could indicate the presence of aromatic species, probably phenylalanine $(\sim 1.4 \%)$ and tyrosine $(\sim 0.5 \%)$.

An ESI-MS characterization study was performed in order to investigate more deeply the nature of the oligopeptides present in Extract 3. As the spectroscopic results have shown the presence of protein in Extract 3 and, in particular, they have identified hydrolyzed gelatin (collagen) as the main component of the sample, all the ESI-MS $m / z$ values, reported in Table 6, were attributed considering the collagen structure and amino acid composition.

The elemental analysis (Table 5) shows that Extract 3 has the highest $\mathrm{N}$ ratio among the three samples. The $\mathrm{N}$ ratio calculated from the molecular formula of collagen is about

Table 6 Results of ESI-MS in positive mode of Extract 3

\begin{tabular}{llll}
\hline Observed mass & Type & Calculated mass & Hypothetic composition \\
\hline 173.0939 & {$[\mathrm{M}+\mathrm{H}]^{+}$} & 173.0999 & $1 \mathrm{G}, 1 \mathrm{P}$ \\
203.5651 & {$[\mathrm{M}+\mathrm{H}+\mathrm{Na}]^{2+}$} & 203.0941 & $3 \mathrm{G}, 2 \mathrm{P}$ \\
211.5511 & {$[\mathrm{M}+\mathrm{H}+\mathrm{Na}]^{2+}$} & 211.0916 & $3 \mathrm{G}, 1 \mathrm{P}, 1 \mathrm{Hyp}$ \\
224.0763 & {$[\mathrm{M}+2 \mathrm{H}]^{2+}$} & 224.1144 & $3 \mathrm{G}, 1 \mathrm{~A}, 1 \mathrm{~W}$ \\
232.0645 & {$[\mathrm{M}+\mathrm{H}]^{+}$} & 232.1406 & $3 \mathrm{~A}$ \\
270.1667 & {$[\mathrm{M}+\mathrm{H}]^{+}$} & 270.1562 & $1 \mathrm{G}, 2 \mathrm{P}$ \\
317.2212 & {$[\mathrm{M}+\mathrm{H}]^{+}$} & 317.1606 & $2 \mathrm{G}, 1 \mathrm{~A}, 1 \mathrm{Hyp}$ \\
354.1328 & {$[\mathrm{M}+\mathrm{Na}]^{+}$} & 354.1571 & $2 \mathrm{G}, 3 \mathrm{~A}$ \\
362.1012 & {$[\mathrm{M}+2 \mathrm{H}]^{2+}$} & 362.1933 & $6 \mathrm{G}, 1 \mathrm{~A}, 3 \mathrm{P}$ \\
365.1322 & {$[\mathrm{M}+\mathrm{Na}]^{+}$} & 365.1582 & $2 \mathrm{G}, 1 \mathrm{~A}, 1 \mathrm{P}$ \\
391.2826 & {$[\mathrm{M}+\mathrm{H}]^{+}$} & 391.1763 & $2 \mathrm{G}, 1 \mathrm{P}, 1 \mathrm{~F}$ \\
401.2001 & {$[\mathrm{M}+\mathrm{H}]^{+}$} & 401.2002 & $5 \mathrm{G}, 1 \mathrm{P}$ \\
489.6904 & {$[\mathrm{M}+\mathrm{H}]^{+}$} & 489.2315 & $4 \mathrm{G}, 1 \mathrm{P}, 1 \mathrm{~F}$ \\
533.2515 & {$[\mathrm{M}+\mathrm{Na}]^{+}$} & 533.2553 & $2 \mathrm{G}, 2 \mathrm{~A}, 1 \mathrm{P}, 1 \mathrm{Hyp}$ \\
570.1923 & {$[\mathrm{M}+\mathrm{H}]^{+}$} & 570.2777 & $4 \mathrm{G}, 1 \mathrm{P}, 2 \mathrm{Hyp}$ \\
618.2118 & {$[\mathrm{M}+\mathrm{H}]^{+}$} & 618.2778 & $6 \mathrm{G}, 1 \mathrm{~A}, 1 \mathrm{~W}$ \\
698.2758 & {$[\mathrm{M}+\mathrm{H}]^{+}$} & 698.3435 & $2 \mathrm{G}, 5 \mathrm{~A}, 1 \mathrm{P}, 1 \mathrm{Hyp}$ \\
748.4337 & {$[\mathrm{M}+\mathrm{Na}]^{+}$} & 748.3568 & $3 \mathrm{G}, 3 \mathrm{~A}, 1 \mathrm{P}, 2 \mathrm{Hyp}$
\end{tabular}


$15 \%$. The $\mathrm{N}$ ratio of Extract 3 is lower (10\%) because of the presence of a small amount of cellulose oligomers, as suggested by the NMR analysis, but confirms the high content of protein in this sample.

Therefore, the spectroscopic and chemical analyses indicate that the cellulose structure of the leaves, from which Extract 3 was obtained, is almost undamaged, as cellulose degradation by-products were not the main components in the wash water of these leaves. The EPR spectrum of Extract 3 (not reported) does not present signals assignable to $\mathrm{Fe}(\mathrm{III})$ or $\mathrm{Cu}(\mathrm{II})$. Accordingly, the ICP-MS values (Table 4) show that Extract 3 presents the lowest iron content, and the content of aluminum, a metal active in catalyzing hydrolysis, is lower in Extracts 2 and 3 than in 1.

Generally, the different amounts and types of metal ions detected in Extract 1 and 2 can explain the different degradation levels of the leaves, from which the extracts were collected. On the other hand, the $\mathrm{Al}$ content of Extract 3 is very close to the one detected in Extract 2, while the Fe amount is slightly lower (mostly present as Fe(II) or iron oxides, as no isolated Fe(III) EPR signal was detected). As the metal amount in Extract 3 is very close to the Extract 2 one, the highly persevered state found in the leaves, from which Extract 3 was obtained, is mainly due to the high amount of gelatin used in the leaf sizing, confirming in this way the literature data. ${ }^{9-11,14,15}$ The data, as a whole, suggest that gelatin, by permeating the paper fibers, is more directly in contact with air and polluting agents, and thus can somewhat protect the fibers from oxidation and acidic hydrolysis by acting as a sink for the reactants. It is also possible to deduce that these leaves belonged to a different paper ream from that of the other leaves, from which Extracts 1 and 2 were obtained.

A further hypothesis could suggest that gelatin has protected the cellulose chain from oxidation, ${ }^{11}$ avoiding the formation of carboxylate groups: indeed, these latter are able to form stable distorted complexes with $\mathrm{Fe}(\mathrm{III})$, allowing it to act as a catalyst for the degradation reactions.

As well, these results are consistent with the measured $\mathrm{pH}$ values (Table 1), as the most degraded leaves, showing a more acidic $\mathrm{pH}$, dissolve in the extract solution a larger amount of metal ions than the least degraded leaves.

The difference in $\mathrm{pH}$ among the three samples also explains the upstream results of the PDA-CE analysis: the quantification results (Table 2) demonstrated that the aqueous extracts obtained from the book sheets under good conservation conditions (Extract 3) had the highest yield in total LMMOA degradation products. These unexpected results could be due to the different $\mathrm{pH}$ of the three samples: given the $\mathrm{p} K_{\mathrm{a}}$ of the LMMOA, it is likely that in the paper the equilibrium was shifted to the deprotonated form in Extract 3 more than in the other two extracts. Carboxylates are largely nonvolatile as opposed to carboxylic acids. Acids in Extracts 1 and 2 may have off-gassed continuously from the leaves upon their production even before the paper was washed, whereas in Extract 3, being the carboxylate ions predominant, they could stay in situ and could thus be extracted during the washing.

\section{Conclusions}

In this work, it has been demonstrated that wash waters used in common deacidification treatments of books in restoration workshops are rich in degradation by-products. The study has also shown that the analysis of these by-products could provide useful indications on the "health" of an ancient book. However, we must point out that a full validation of the method will require us to relate the type of by-product in the water extracts to composition and degradation level of the leaves: the level of degradation in the leaves should be reliably assessed through quantifiable parameters (DP, yellowing index, etc.), which was unfortunately impossible in the present case. Also, compositional parameters (like gelatin content, metal ions, etc.) are relevant, and should be assessed on the leaves before and after the treatment. E.g., the presence of gelatin in the less degraded leaves was guessed on the basis of the by-products from the water extracts, but its actual presence on these leaves should be confirmed by direct examination, as well as its absence on the most degraded. Finally, the study should be performed on a statistically significant number of ancient books. Once validated, the proposed protocol could be very useful, since it perfectly integrates into the book conservation workshop, which acquires in this way an added value, as it slows down the book degradation but, at the same time, recovers waste materials which can provide precious information about the degradation pathways responsible for book deterioration.

Since many restoration workshops are present in Italy and Europe, and a large amount of leaves from ancient books are treated in this way, a planned collection of wash waters from the different ateliers could provide a large database of degradation by-products.

The main by-products formed on the most damaged leaves of the book De Divina Providentia are strongly oxidized and unsaturated cellulose oligomers, while the analyses performed on the water extracts of the not degraded sheets have further confirmed and highlighted the role of gelatin in protecting the paper over centuries. The type and amount of metal ions detected in Extract 1 and 2 reflects the high degradation level and dark color shown by the leaves, from which they were extracted. However, the amount of metal ions detected in Extract 3 is quite high, once correlated to the good conservation state of its leaves, underlining the advantages of proper sizing toward the preservation of ancient paper. In general, the differences in composition between the most degraded samples and the not degraded one suggest that the sheets, from which the analyzed solutions were extracted, could belong to different reams. This is not the only possible explanation, but it is sensible, as generally several reams of paper were used for the assembly of a single book.

\section{Acknowledgements}

We are deeply thankful to Mrs Emanuela Zangirolami and Mrs Sabrina Mattiolo for their technical contribution. We are thankful to Dr Danilo Pedron for the FTIR measurements, Dr 
Ileana Menegazzo for the NMR measurements and Dr Luca Nodari for the XRF measurements.

\section{References}

1 E. Buringh and J. L. Van Zanden, J. Econ. Hist., 2009, 69, 409. 2 R. L. Feller, S. B. Lee and J. Bogaard, in Historic Textile and Paper Material. Conservation and Characterization, ed. H. L. Needles and S. H. Zeronian, ACS, Philadelphia, 1986, pp. 329-346.

$3 \mathrm{H}$. Krässig, in Cellulose and its Derivatives. Chemistry, Biochemistry and Applications, ed. J. F. Kennedy, G. O. Phillips, D. J. Wedlock and P. A. Williams, Ellis Horwood Ltd, Chichester, 1985, pp. 3-25.

4 M. Strlič and J. Kolar, Aging and Stabilisation of Paper, ed. M. Strlič and J. Kolar, National and University Library, Ljubljana, 2005, pp. 5-7.

5 W. J. Barrow, Permanence/Durability of the Book-VII, Physical and Chemical Properties of Book Papers, W. J. Barrow Research Laboratory, Richmond, 1974, pp. 1507-1949.

6 D. Diderot and J. B. Le Ronde D'Alembert, Encyclopédie ou Dictionnaire raisonné des sciences, des arts et des métiers, par une Société de Gens de lettres, Samuel Faulche et Compagnie, Neufchatel, 1765, vol. 11, pp. 1751-1772.

7 A. Courts, in Applied Protein Chemistry, ed. R. A. Grant, Applied Science, London, 1980.

8 W. K. Wilson and E. J. Parks, Restaurator, 1983, 5(3-4), 191241.

9 T. Barrett and C. Mosier, J. Am. Inst. Conserv., 1995, 34, 173186.

10 T. Barrett, Paper Conservator, 1989, 13, 1-108.

11 C. H. Stephens, T. Barrett, P. M. Whitmore, J. A. Wade, J. Mazurek and M. Schilling, J. Am. Inst. Conserv., 2008, 47, 201-215.

12 J. Tétreault, A.-L. Dupont, P. Bégin and S. Paris, Polym. Degrad. Stab., 2013, 98, 1827-1837.

13 E. Menart, G. de Bruin and M. Strlic, Cellulose, 2014, 21, 3701-3713.

14 A.-L. Dupont, J. Chromatogr. A, 2002, 950, 113-124.

15 A.-L. Dupont, Ph.D. thesis, University of Amsterdam, Amsterdam, 2003.

16 J. Kolar, A. Štolfa, M. Strlič, M. Pompe, B. Pihlar, M. Budnar, J. Simčič and B. Reissland, Anal. Chim. Acta, 2006, 555, 167174.

17 J. Kolar, M. Sala, M. Strlic and V. S. Šelih, Restaurator, 2005, 26, 181-189.

18 K. Janssens, V. Rouchon-Quillet, C. Remazeilles, M. Eveno and A. Wattiaux, in Durability of Paper and Writing, Proceedings of the International Conference, Ljubljana, Slovenia, 16-19 November 2004.

19 V. Rouchon-Quillet, C. Remazeilles, L. Fournes and A. Wattiaux, in International Conference of Chemical Technology on Wood, Pulp, and Paper, Section "Paper in Archives and Libraries", Proceedings of the International Conference, Bratislava, Slovakia, 17-19 September 2003.

20 M. Bicchieri and S. Pepa, Restaurator, 1996, 17, 165-183.
21 U. Henniges, R. Reibke, G. Banik, E. Huhsmann, U. Hähner, T. Prohaska and A. Potthast, Cellulose, 2008, 15(6), 861-870.

22 J. C. Williams, C. S. Fowler, M. C. Lyon and T. L. Merrill, in Preservation of Paper and Textiles of Historic and Artistic Value. Adv. Chem. Series 194, ed. J. C. Williams, ACS, Washington D.C., 1977, pp. 37-61.

23 C. J. Shahani and F. H. Hengemihle, in Historic Textile and Paper Materials. Conservation and Charaterization, ed. $\mathrm{H}$. Needles and S. H. Zeronian, ACS, Philadelphia, 1986, pp. 387-410.

24 J. A. Emery and H. A. Schroeder, Wood Sci. Technol., 1974, 8, 123-137.

25 R. G. Veness and G. S. Evans, in Cellulosics: Pulp, Fibre and Environmental Aspects, ed. J. F. Kennedy, et al., Hornwood, New York, 1993, pp. 451-456.

26 D. Attanasio, D. Capitani, C. Federici and A. L. Segre, Archaeometry, 1995, 37, 377-384.

27 D. Attanasio, D. Capitani, C. Federici and A. L. Segre, in Multidimensional Spectroscopy of Polymers, ed. M. W. Urban and T. Provder, ACS, Washington, 1995, pp. 335-353.

28 A. Zoleo, D. Confortin, N. Dal Mina and M. Brustolon, Appl. Magn. Reson., 2010, 39, 215-223.

29 A. Zoleo, F. Vecchia and M. Brustolon, Appl. Magn. Reson., 2009, 35, 213-220.

30 M. Bronzato, P. Calvini, C. Federici, S. Bogialli, G. Favaro, M. Meneghetti, M. Mba, M. Brustolon and A. Zoleo, Chem.-Eur. J., 2013, 19, 9569-9577.

31 M. Bicchieri, A. Sodo, G. Piantanida and C. Coluzza, J. Raman Spectrosc., 2006, 37, 1186-1192.

32 L. Bellot-Gurlet, S. Pages-Camagna and C. Coupry, J. Raman Spectrosc., 2006, 37, 962-965.

33 V. Amendola and M. Meneghetti, J. Mater. Chem., 2007, 17, 4705-4710.

34 Z. Souguir, A.-L. Dupont and E. R. de la Rie, Biomacromolecules, 2008, 9, 2546-2552.

35 A.-L. Dupont, C. Egasse, A. Morin and F. Vasseur, Carbohydr. Polym., 2007, 68, 1-16.

36 P. Calvini and A. Gorassini, Restaurator, 2002, 23, 48-66.

37 J. Łojewska, M. Missori, A. Lubańska, P. Grimaldi, K. Zięba, L. M. Proniewicz and A. Congiu Castellano, Appl. Phys. A, 2007, 89, 883-887.

38 T. Łojewski, P. Miśkowiec, M. Missori, A. Lubańska, L. M. Proniewicz and J. Łojewska, Carbohydr. Polym., 2010, 82, 370-375.

39 M. Ali, A. M. Emsley, H. Herman and R. J. Heywood, Polymer, 2001, 42, 2893-2900.

40 T. Łojewski, K. Zięba, A. Knapik, J. Bagniuk and J. Łojewska, Appl. Phys. A, 2010, 100, 809-821.

41 M. R. Derrick, D. Stulik and J. M. Landry, in Infrared Spectroscopy in Conservation Science, The Getty Conservation Institute, Los Angeles, 1999.

42 J. Łojewska, T. Miśkowiec, L. Łojewski and M. Proniewicz, Polym. Degrad. Stab., 2005, 88, 512-520.

43 P. Calvini, A. Gorassini, G. Luciano and E. Franceschi, Vib. Spectrosc., 2006, 40, 177-183.

44 A.-L. Dupont, Restaurator, 1996, 17, 145-164.

45 A.-L. Dupont, Restaurator, 1996, 17, 1-21. 
46 M. Martinez, G. León de Pinto, L. Sanabria, O. Beltran, J. M. Igartuburu and A. Bahsas, Carbohydr. Res., 2003, 338, 619-624.

47 L. A. Flugge, J. T. Blank and P. A. Petillo, J. Am. Chem. Soc., 1999, 121, 7228-7238.

48 K. M. Benabdillah, J. C. Mahfoud Bousetta, R. Engel and M. Vert, Macromolecules, 1999, 32, 8774-8780.

49 C. W. Higham, D. Gordon-Smith, C. E. Dempsey and P. M. Wood, FEBS Lett., 1994, 351, 128-132.
50 O. Marcq, J. M. Barbe, A. Trichet and R. Guilard, Carbohydr. Res., 2009, 344, 1303-1310.

51 O. Marcq, J. M. Barbe, A. Trichet and R. Guilard, Carbohydr. Res., 2001, 333, 233-240.

52 R. Wiltscheck, R. A. Kammerer, S. A. Dames, T. Schulthess, M. J. J. Blommers, J. Engel and A. T. Alexandrescu, Protein Sci., 1997, 6, 1734-1745.

53 H. Saitò and M. Yokoi, J. Biochem., 1992, 111, 376-382. 